\section{GEOLOGY AND GEOLOGISTS IN THE NATIONAL WAR EFFORT}

\author{
By PROF. H. H. READ, F.R.S. \\ Imperial College of Science and Technology
}

$\mathrm{T}$ HERE appears to be considerable divergence of opinion among professional geologists in Great Britain as to the extent to which they and their knowledge can be used in war. Some hold that hundreds of geologists could be employed in the civil defence and armed forces; others protest that saturation would be reached by the employment of a score or so. Whatever may be the truth of this matter, however, all are agreed that the utilization of geological knowledge in the war effort has up to now been singularly haphazard. It is, of course, possible that a considerable proportion of the cases of the successful use of such knowledge never becomes public, while certain scandalous examples of neglect of geological information achieve, on account of their news value, a disproportionate notoriety. Still, if there were but one case of such neglect, the geologist would be entitled to lift up his voice. When he is officially informed that a sum approaching half a million pounds has been wasted through this cause at one aerodrome site alone, he must be pardoned if he becomes speechless, and especially so since, though he may faintly hope that those officials responsible for this waste have been liquidated, he is secretly sure that they have been promoted to posts with still greater possibilities.

As Prof. P. G. H. Boswell has pointed out in his presidential address to the Geological Society, issued on September 30, the fundamental reason for this haphazard utilization of geological knowledge is the lack of awareness on the part of the general publie of the content of the science. The ignorance is, of course, especially profound among the politicians and the higher Civil Servants, while among scientific men it is often deplorable-a result in their case arising from a devotion, inculcated in the schools and fostered by examination requirements, to the unholy trinity of mathematics, physics and chemistry. One would have expected, on the grounds of value for money alone, a fuller utilization of geological knowledge which, in predominant proportion, has been accumulated and is being correlated and curated through the use of public funds of one kind or another. There is, however, little to be gained by elaborating this jeremiad, and we can with greater profit turn to the contemplation of such uses as have been made of geology and geologists in the war effort.

Large-scale industry, the sustainer of modern mechanical warfare, is founded upon iron ore and the solid and liquid natural fuels. Vital for the full development of its power, however, is a great variety of strategic mineral products, such as the alloy metals, the important non-ferrous metals, and a group of non-metallic minerals chiefly of a refractory or abrasive character. Further, food is a munition of war, and in consequence the mineral fertilizers are of strategic importanee too. This fundamental dependence of industry upon mineral products becomes a lively topic during a time of mechanical warfare when it is impressed upon the political and Civil Service hierarchy that minerals are not evenly distributed among the nations, that supplies of vital raw materials are liable to interruption or even stoppage and that, in any event, minerals are bulky commodities usually requiring lengthy transport. A modern State, bent upon modern war, would naturally accumulate reserves of strategic minerals sufficient for the estimated duration of the conflict. We may be sure that the Axis has affected this obvious insurance, and that prophecies of an Axis shortage of oil, of some alloy metal or of some other strategic mineral product are liable to falsification.

An effort for autarky, or for the transformation of a peasant State into an industrial one, depends for success upon the discovery within the borders of the State of mineral resources of suitable size, character and variety. In this connexion, it may be recalled that thousands of geologists have been employed in mineral prospecting and development in the U.S.S.R. during the last twenty years. Their efforts have had remarkable successes; there have been notable and constant increases in Soviet mineral production, both in amount and variety. In NATURE of Oetober 25, Prof. A. E. Fersman recorded that during the last quarter of a eentury, 75,000 new mineral fields were discovered in the U.S.S.R., that the known coal resources had been increased ten times, the resources of iron ore thirty-three times, and of lead and copper more than ten times. Fundamentally, therefore, the heroic Soviet resistance is possible because of the field-work of the Soviet geologists. It is my opinion that the most important use of British and American geologists in the war effort is to be found in the continuance of their jobs, often unheroic, of finding new mineral deposits and of developing maximum production of the required. grades from these and the old fields. If the Allies hold on, it is comforting to reflect that the mineral resources of the British Empire, the U.S.S.R. and the United States are complementary to an extraordinary degree, while those of the Axis are thoroughly lopsided and, in the cases of the two junior partners, practically non-existent.

The interruption of supplies from overseas and the difficulties of transport have naturally led to renewed investigation, followed by development where possible, of native British mineral resources. In this work the dominant part is played by H.M. Geological Survey which, during its century of existence, has accumulated a vast store of information concerning mineral possibilities in Great Britain. The resources of coal and iron ore, the basic requirements of industry, have continued to be investigated in detail, while much attention has been directed to the discovery and workability of such ancillary metals and non-metallic minerals as this country can supply.

The results of a number of these investigations are given in the War-time Pamphlets issued by the Survey, which deal, in this connexion, with iron ores of various kinds, felspar, diatomite, dolomite and brucite-marble, silica-rock, phosphates, talc, chromite and limestones. This list, of course, by no means covers the complete field explored. It is gratifying to learn that production is taking place from mineral deposits discovered and investigated by the Survey. One success that may be mentioned is the find of a sand in Morvern, Scotland, suitable for optical glass and equal in quality to the best Continental sands, which is being worked on a considerable scale. In this type of investigation, the Survey is often helped by university and other geologists who have the advantage of detailed local knowledge. Such geologists, too, are being consulted on special problems of supply by Government and other bodies. In addition to investigations such as those mentioned, the 
Survey deals with routine inquiries, some of which entail lengthy researches. A service of a similar nature dealing largely with inquiries from the Dominions, India and the Colonies is provided by the Mineral Resources Department of the Imperial Institute. This Department publishes monographs on economic minerals and valuable statistical reports on world mineral production.

The staff of the Geological Survey, however, is limited in number, its members rarely reside for long in any particular place, and they are unable, therefore, to record the innumerable temporary sections and exposures that are constantly being produced. The local geologist, whether university or lay, has opportunities of acquiring a detailed knowledge, especially of the superficial deposits, which is denied to his Government colleague. It is to the local geologist that the civil authorities, if necessary through the offices of the regional commissioner, should turn for geological information on such matters as the proper siting of shelters, supplies of sand, and questions of a kindred nature. So far as. I am aware, this has been done in few cases; the results of this neglect can be seen all over the country. A similar absence of consultation between the military authorities and local geologists is indicated, for example, by the flooding of military works, the perilous position of certain tank blocks especially along rivers, and the instability of costly excavations. It is happier to record that in a few cases this desirable liaison has been established. Good work was done by some local geologists in indicating sources of sand for sandbag-filling in the early days of the War. Moreover, hundreds of thousands of pounds were saved in transport costs in London alone by following advice on the location of sand deposits given by the Geological Survey.

A very important war-time activity of the Geological Survey is connected with water supply, and many of the War-time Pamphlets deal with supplies from underground sources for various parts of the country. Movements of population, the formation of great military camps and aerodromes, and the construction of immense factories all raise problems in water-supply. Time was when a camp site was decided upon and then a water-supply demanded, but $I$ understand that this procedure has now been changed. It is obvious that an accurate assessment of the present supply from underground sources, of emergency and even long-range supplies, has to be made, and especially in the so-called invasion areas. Piped supplies are liable to interruption by enemy action, and so the storage of water for fire-fighting in vulnerable districts may give rise to geological inquiry.

At the beginning of these remarks, I recalled the case of the scandalous neglect of geological advice at an aerodrome site, and I repeat that as complete a knowledge as possible of the geological conditions, both as regards water supply and foundation factors, at sites projected for costly camps, aerodromes and factories, is an obvious precaution. The Geological Survey and non-Government geologists are engaged in a certain amount of preventive work along these lines.

Readers of the more popular Press may have seen very remarkable accounts of some of the underground factories, stores and the like which have been constructed. Before the expenditure of vast sums of money on these great mining and engineering works, with their attendant housing and transport schemes, it is clearly a matter of common-sense to study in detail the prime control, the nature of the rocks and their arrangement. Here, again, the geologist has been utilized. The roughness of the geological story of Great Britain has resulted in our possessing a great number of suitable rocks suitably arranged for this purpose. A similar foresight is necessary in the construction of deep air-raid shelters and, again, most of our large towns have a fortunate geological past. At this point, non-geologists should ponder as to why London has its Underground, and draw a little comfort in these hard times.

What has been said above deals largely with the use, or non-use, of geological knowledge, but it has also been suggested that the best use of the geologist is to let him carry on with his asual work. This suggestion has not always been followed, and often it is the geologist himself who decides on a change of occupation. In certain branches of the Forces, a geological training is an advantage. All geologists can read maps and most can make them, some are expert drillers and others are familiar with mining and excavation methods. Men who havè earned their living for years by the interpretation of arrial photographs should be employed in similar work in the Services. I have heard of an ex-geologist airman who finds his way about above England by his geological knowledge. There is a niche somewhere in camouflage for a geologist who will prevent the breaking of all geological rules in one small scheme, just as in happier times Hollywood might be persuaded to hire a geologist who would make sure that a film alleged to be in a Jerusalem setting would be set in Jerusalem geology, and not in that of California.

Such are some of the ways, then, in which geological knowledge and geologists are and are not being used in the war effort. The full employment of both can follow only from an adequate realization by the directorate of the possibilities of service.

\section{MECHANISMS OF VISION \\ BY PROF. SELIG HECHT}

\section{Department of Biophysics, Columbia University}

$T$

HE symposium on visual mechanisms held on September 24 during the Fiftieth Anniversary Celebrations of the University of Chicago brought together some of the diverse methods and points of view found in the study of vision. Of the eight papers, three were concerned with the structures, materials and energy relations of the eye itself; one considered vision merely as an indicator of the state of the nervous system under anoxia; while the other four explored the relations between sensory phenomena and the central nervous system.

The morning session began with a report by Prof. Selig Hecht on the minimum energy required for vision. New determinations made under the best physical and physiological conditions yield values between $2 \cdot 2$ and $5 \cdot 7 \times 10^{-10}$ ergs, which correspond to 58 and 148 quanta of blue-green light (510 $\mathrm{mu}$ ). This is at the cornea. After corrections for reflexion from the cornea, for scattering and absorption by the ocular media, and for transmission by the retina, the range of 58-148 quanta at the cornea becomes 5-14 quanta absorbed by the retina. Since the stimulated 